\title{
Perception Analysis of Silver Jubilee Grade- Separated Intersection in Kano Metropolis Using Context Sensitive Solutions
}

\author{
A. Muhammad, M. N. Ibrahim* \\ Department of Civil Engineering, Bayero University, Kano, Nigeria.
}

ABSTRACT: This study explores the users' perception on operational performance of Silver Jubilee Grade Separated Intersection (SJGSI) in Kano Metropolis using Context Sensitive Solutions (CSS). The CSS seeks to provide a transportation facility that fits its setting, leading to the preservation and enhancement of scenic, aesthetic, environmental and community resources while maintaining safety, mobility and comfort. A structured questionnaire enquired the opinion of respondents, among others, on the optimal performance of SJGSI and its determinants. Three correlation analyses and two regression analyses were generated. The results showed that most of the correlating and regressing variables are weakly correlated by chance. The degree of familiarity correlated with number of motorists (users) has an R-value of 0.125; the optimal performance correlated with its cost worthiness has an R-value of 0.166. The general and Context Sensitive (CS) optimal performance model has an R-values of 0.415 and 0.374, respectively. Some of the weak correlations could be attributed to the facility not planned based on CSS approach. A CS facility could have received a higher optimal performance rating, approval rating and CS features' rating with increased efficiency and effectiveness. Most respondents opined that a better facility would have been constructed if all relevant stakeholders were involved in the development processes.

KEYWORDS: Context sensitive solutions, Context-sensitive, Correlation, Regression, Optimal, Stakeholders

\section{INTRODUCTION}

In third world countries such as Nigeria, many times governments at various levels embark on projects with little (if any) consultation and collaboration with the relevant stakeholders involved in the planning, design, construction and maintenance of such projects. As a result, projects that are not of the highest priority and probably unwanted by the majority of the public citizens are executed, unfortunately giving rise to underperformance and perpetual underdevelopment.

A common technique that incorporates input from the relevant stakeholders in the provision of a transportation facility which could effectively satisfy the intended purpose of the facility is Context Sensitive Solutions (CSS). According to the Maryland Department of Transportation (MDOT, 1998), CSS is a collaborative, interdisciplinary approach that involves all the relevant stakeholders to provide a transportation facility that fits its setting. It is an approach that leads to preserving and enhancing scenic, aesthetic, historic, community, and environmental resources, while improving or maintaining safety, mobility, and infrastructure conditions.

In Kano Metropolis, many users of Silver Jubilee GradeSeparated Intersection (SJGSI) find it challenging and difficult to achieve optimal mobility with highest efficiency and comfort. The facility is a double cloverleaf grade-separated intersection (flyover) having an approximate length of $692 \mathrm{~m}$ that connects six (6) major urban arterials to minimize traffic conflict as well as improve operational performance within the area. Information obtained through personal interaction revealed that many users complain about the difficulty in accessing and exiting some of the slip roads due to their narrowness. For example, occasional traffic delay builds up around the entry slip road connecting Bayero University, Kano (BUK) Road and State Road via the grade separation portion. This noticeable delay instigates users to wonder whether the facility is performing as it should be.

Inadequate or lack of involvement of the relevant stakeholders in the transportation planning process could lead to underperformance of such facilities to users. A correlation exists between the transport planning process and the operation of a transport facility (Michael, 2016; Xia, 2014). If a facility is generally accepted and it performed optimally, comfortably and conveniently, it is assumed that a robust and wide range stakeholder involvement was carried out at the planning stage. The involvement of the relevant stakeholders in transport decision-making processes is one of the key elements of sustainable mobility planning. A more effective and efficient transport plan is developed when stakeholders are adequately involved in any planned project. It is a fundamental duty of the authorities concerned to involve the relevant stakeholders to improve decision-making (Böhler-Baedeker and Lindenau, 2013). 
As a multi-dimensional process that has evolved from context sensitive-design (CSD), CSS comprises innovative thinking, improved coordination and communication, and interdisciplinary decision-making processes of project development and implementation (GDOT, 2016). CSS is an approach that considers the total context within which a transportation improvement project will exist (FHWA, 2017). The Virginia Department of Transportation (VDOT, 2016) defined CSS as a project development approach that promotes the involvement of all relevant stakeholders in the development of a transportation facility that fits its physical setting and also reflects concerns for scenic, aesthetic, historic and environmental resources while providing for transportation safety and mobility.

From the inception and planning through operations and maintenance, CSS provides an orderly and comprehensive approach to project development. Its goal is to achieve a procedural project development that produces a harmonising outcome between transportation requirements with community needs and values. Due to this, CSS has been promoted as a best practice in transportation development by the American Association of State Highway and Transportation Officials (AASHTO) and Federal Highway Administration (FHWA) (Stamatiadis et al., 2009).

Public involvement is fundamental for a successful CSS. Rigorous and effective involvement of the public encourages and enhances the discovery of an issue from a variety of perspectives. Community representatives and users need to be identified from the onset of the project, during the planning, design and development processes. Stakeholders need to be involved throughout these processes. It was argued also that all projects need some form of public outreach. However, on smaller projects, the public needs to be notified of upcoming projects that will affect them (MDT, 2015).

Stakeholders in both the transportation industry and community groups are collaborating to achieve greater design flexibility and the integration of community values in CSS. Highway projects once focused almost exclusively on faster travel times and safety and were perceived as having adverse impacts on communities through which they passed. Recent AASHTO and FHWA publications provide ideas, options, and examples of ways to design highways that are more environmentally friendly without compromising safety and mobility. They stress the importance of eliciting early public participation, identifying community interests, and using creative thinking to achieve community-friendly highway design (Wolf, 2006).

Al-Kaisy and Roefaro (2012) reported that CSS guidelines serve as a source of guidance in determining the use of channelized right lane turning movement at signalised intersections, which is one of the treatments of the right-turning movements at intersections. CSS allows a new traffic design concept called shared space which involves the removal of traditional signs, signals and lines in combination with the shared use of the same area by different vulnerable users of a facility. In this way, a user of a facility is forced to choose his speed taking into account the behaviour of other users. CSS also allows the coherent and integrated consideration of

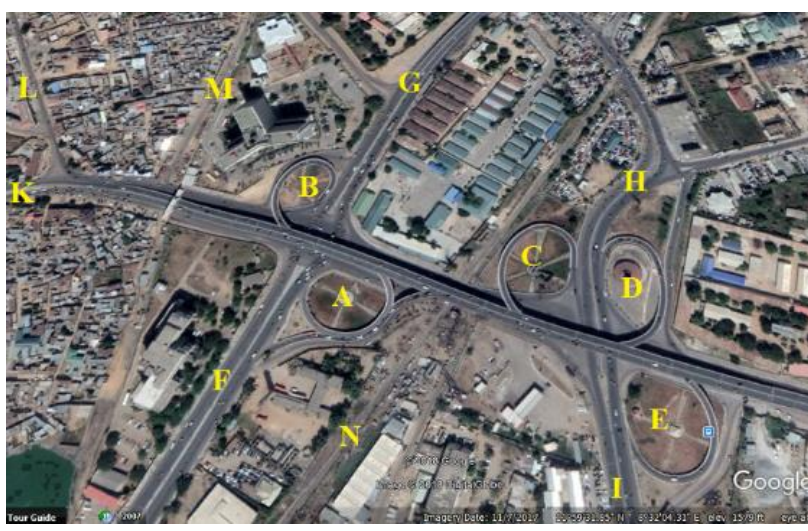

Figure 1: Aerial Satellite View of SJGSI.

regional bike planning as a strategic component of territorial planning (Dondi et al., 2011).

Furthermore, CSS allows for increased flexibility in design to better understand complex trade-offs. It is no longer sufficient to design a road to reduce congestion and improve safety and mobility for automobiles using standard procedures and charts from a design manual. Transport engineers must now also consider the needs of pedestrians and bicyclists of all ages, and balance cost, safety and mobility with historical, cultural and environmental contexts. A CS approach creates the opportunity to consider the unique land-use context of the road and the area's valued characteristics, while weighing complex design choices with the related risk. Through this multidisciplinary process, the needs of older road users can be established as fundamental parameters for design (Classen $e t$ al., 2011).

A gap exists between the CSS principle and the project development stages. Worldwide, CSS is being applied and implemented only at the planning and conceptualization stage of a transportation project, with little (if any) review and referencing during the construction and monitoring. To fill this gap and contribute to the existing pool of knowledge, this research investigated public complaints regarding the users' perceived operational perception of the users of SJGSI and the outcome was used to determine whether extensive stakeholder involvement was incorporated at the conceptualisation stage of the project or otherwise. The aim of the work was to evaluate the degree of correlation between the planning and operational stages of SJGSI using CSS. Specifically, to determine whether public complaints about the operational performance of SJGSI are valid and whether CSS was employed during the planning of the project as well to establish whether there exists a correlation between the planning and the users' perception about the performance of the facility.

\section{A. Study Area}

\section{METHODOLOGY}

The SJGS is roughly located on latitude $8.54^{\circ}$ and longitude $11.99^{\circ}$ in Kano State, Nigeria. It is a double cloverleaf grade separation that directly links the State Road and Emir's Palace Road. It also connects (at-grade) the everbusy Zaria and Katsina roads via Ibrahim Taiwo Road and Murtala Muhammad Way. The aerial view of the study area is shown in Figure 1. 
Legend: A - Loop A, B - Loop B, C - Loop C, D - Loop D, E - Loop E, F - BUK Old Campus Road, G - Ibrahim Taiwo Road, H - Abdullahi Bayero Road, I - Zaria Road, J - State Road, K - Emir's Palace Road, L - Rimi Market Road, M - Yusuf Maitama Sule University Road, N - Fish Market Road

The main bridge portion consists of 27 spans of $20 \mathrm{~m}$ each, 2 transition slabs of $5 \mathrm{~m}$ each, a $65 \mathrm{~m}$ retaining wall portion on Emir's palace Road and a $76.7 \mathrm{~m}$ retaining wall portion on the State Road. The SJGSI facility has a total length of $691.7 \mathrm{~m}$ from the beginning of the retaining wall along the State Road to the end of the retaining wall along the Emir's Palace Road. The facility has five loops; Loop A is adjacent Kano State Fire Service and is comprised of two slip roads entering and exiting the main bridge portion. The slip roads at loop $\mathrm{A}$ are both 322.496 m long. Loop B is adjacent Yusuf Maitama Sule University, City Campus, which is a $187.44 \mathrm{~m}$ exit slip road. Loops $\mathrm{C}$ and D contained an almost identical entry and exit slip roads. While the exit slip road at loop C is $241.429 \mathrm{~m}$ and is adjacent the former Kano Basketball Stadium, the entry slip road at loop D is adjacent Kano Technical College and it is $239.63 \mathrm{~m}$ long.

\section{B. Questionnaire Design}

After extensively reviewing the attributes of a good questionnaire design as documented (Burgess, 2001; Siniscalco and Auriat, 2005; Stefanowski, 2013) and establishing the type and scope of the required data, a qualitative questionnaire for the research was designed. The questionnaire was partitioned into three parts consisting of a mix of close-ended and open-ended questions. The partitioning of the questionnaire was built upon the fact that two broad groups of respondents were considered; comprising of (i) Non-Civil Engineers and (ii) Civil Engineers.

Part A of the questionnaire formed the general section in which everyone was expected to respond. Part B is exclusively for non-engineers comprising of civil servants, contractors, consultants, planners, etc. This category of respondents consisted of one of the most intellectual and literate individuals in society. The category is also one of the most important categories of stakeholders that are expected to be consulted in any transportation initiative by government. Part $\mathrm{C}$ of the questionnaire formed the technical part in which only civil engineers responded to the inquiry. The questionnaire can be accessed through https://rive.google.com/file/d/1eoz2R4pKQhT5wjbs6KaIG $\underline{\text { Rf4_WVSlkRR/view? usp=drivesdk. }}$.

\section{Questionnaire Sample Size Determination}

The target population is assumed to be, at least, fairly familiar with SJGSI. It is very difficult to accurately determine the size of the population. A method was adopted to determine a sample size that is representative of the population which served as a basis for distributing the questionnaires. Cochran (1977) developed a formula for calculating representative sample size for proportions as shown in Eq. (1).

$$
N=\frac{z^{2} p q}{e^{2}}
$$

where: $N=$ minimum number of required sample size, $z=$ selected critical value of desired confidence interval, $p=$ estimated proportion of an attribute that is present in the proportion, $q=$ estimated proportion of an attribute that is absent in the proportion, $e=$ desired level of precision.

The degree of precision is the margin of permissible error between the estimated value and the population values. Because the sample of this research is not perfect, a margin of error of $+/-10 \%$ was assumed. There is no prior research that employed the concept of CSS on the performance analysis of SJGSI to obtain the proportion of the population $(p)$ with a certain attribute. Therefore, a $p$-value of 0.50 denoting maximum heterogeneity was assumed. Thus,

$$
q=1-p=1-0.50=0.50
$$

The confidence level denotes the degree of certainty of the actual mean (for example) falling within the confidence interval. It corresponds to a $z$-score. Suitably, a confidence level of $95 \%$ was assumed and the corresponding $z$-score was found to be 1.96 (from a Z-score table). Therefore, the minimum required sample size was computed as follows:

$$
N=\frac{z^{2} p q}{e^{2}}=\frac{1.96^{2} \times 0.5 \times 0.5}{0.1^{2}}=96 \text { Respondents }
$$

Since the minimum required number (sample size) of respondents is 96, one hundred (100) respondents were targeted for the study to improve upon the sample size accuracy.

\section{Questionnaire Distribution}

The questionnaires were distributed to personnel of the following establishments, among others:

- Kano State MoWHT, No. 1, Commissioner Road, Kano.

- Federal Ministry of Works, Power and Housing, Federal Secretariat, Kano.

- China Civil Engineering Construction Company Nigeria Limited, Bagadawa, Kano.

- Triacta Nigeria Limited, Gwarzo Road, Kano.

- Wuro Associates, Consulting Civil Engineers, Foundation Building, BUK Road, Kano.

- $\quad$ Royal Haskoning DHV Nigeria Limited, Shu'aibu Kazaure Street, Kano.

- Civil Engineering Department, Bayero University Kano.

\section{E. Selection and Sorting of Valid Responses}

The response rate was computed based on Eq. (2).

$$
R=\frac{N_{R}}{N_{A}}
$$


where: $R=$ response rate of the survey, $N_{R}=$ total number of received responses, $N_{A}=$ total number of administered inquiries. Therefore, $R=80.11 \%$, with a value of 141 for $N_{R}$ and 176 for $N_{A}$.

Fryrear (2015) reported that it is generally preferable to get a high response rate $(80 \%$ or higher) from a small, random sample rather than a low response rate from a larger pool of potential respondents. The response rate of $80.11 \%$ for this research appears satisfactory. Out of the 141 responses retrieved from the respondents, 100 valid responses were selected based on the following criteria in order of priority:

(i) Responses with an individual response rate of $100 \%$ were selected.

(ii) Questions 3, 4, 5, 7, 9 and 10 of the questionnaires are considered exceptionally important.

Responses with an individual response rate of $80 \%$ or greater and contain at most one un-responded exceptional question were selected.

Therefore, out of the selected 100 responses, only two respondents did not respond to either of questions 3, 4, 9 and 10. Subsequently, the selected valid responses were serially numbered 1 to 100 . Responses 1 to 30 were non-civil engineers while responses $31-100$ were civil engineers.

\section{F. Entering the Data of the Valid Responses into SPSS Software}

After sorting and selecting the most valid responses of the survey, the data was then inputted into the IBM SPSS Version 25 by coding the responses. In coding the data, broadly, civil engineers were nominally ranked 1 whilst non-civil engineers were nominally ranked 0 . The responses to questions $1,2,4$, $6,8,10,12,14,15,16,19,20,21,22,24$ and 25 were ordinally ranked 5, 4, 3, 2 and 1 respectively. Responses to question 18 were also ordinally ranked 3,2,1 and 0 in their order. The responses to question 27 were subdivided into $27 \mathrm{a}, 27 \mathrm{~b}, 27 \mathrm{c}$, $27 \mathrm{~d}, 27 \mathrm{e}$, and $27 \mathrm{e}$ and were ordinally ranked 3,2 and 1 respectively corresponding to excellent, good and poor. The responses to questions 7, 9, 11, 13 and 26 were scaled 1 and 0 corresponding to yes and no respectively. The responses to questions 3 and 23 were scaled 0 and 1 corresponding to yes and no respectively.

Overall, 13 questions did not receive a response from the respondents probably due to either refusal to answer, unknown answer or unintentional omission. It is a conventional practice to use a missing value code in the cell where there is no response rather than leaving it blank as this may end up being accidentally converted to zero and will ultimately result in errors in the analysis. The number 7 was selected as the missing value code.

\section{G. Analyses and Interpretations}

1) Pearson's product-moment correlation coefficient

Pearson's product-moment correlation coefficient is a parametric test. The hypothesis testing criteria and confidence interval were used to determine whether a significant correlation occurs between two variables. The following convention holds:

(i) A correlation of +1.00 would indicate a perfect positive relationship.

(ii) A correlation of 0.00 would indicate no relationship.

(iii) A correlation of -1.00 would indicate a perfect negative relationship.

While there are no hard-fast rules, Arkkelin (2014) demonstrated that $R$-values greater than 0.50 indicate a strong correlation, around 0.30 indicates a moderate correlation, and less than 0.20 indicate a weak correlation.

Three sets of correlations were conducted on the questionnaire data. These are the responses to (i) Questions 1, 2 and 3, (ii) Questions 7, 9 and 10, and (iii) Questions 19, 21, $22,27 \mathrm{~d}$ and $27 \mathrm{e}$.

The questionnaire data used for the correlation analysis satisfied the assumptions stated by Miller et al. (2002). These assumptions are; the data is ordinally or nominally ranked, the relationship between the variables could be adequately portrayed by straight lines, and the intersection points are normally distributed around the correlation line. It was not anticipated beforehand on whether the correlation will be positive or negative. Therefore, a two-tailed test of significance was specified in the test of significance of the SPSS bivariate correlations window and the $\alpha$-value used was 0.05 .

\section{2) Regression analyses}

Two broad regression models were generated using the SPSS; General Optimal Perceived Performance Model and CS Optimal Perceived Performance Model. Hypothetically, the general optimal users' perceived performance of the facility is dependent on the number of problems experienced by respondents, its purpose of construction, achievement of the purpose of construction, its cost worthiness and rating as perceived by the respondents. The responses of the total respondents were used in generating this regression model. Similarly, context-wise, the CS perceive performance model is dependent on the main CSS outcomes and benefits. These include, but not limited to, the preservation of historic features at the facility's location, preservation/enhancement of scenic, aesthetic and environmental features, maintaining/improving safety and mobility, and sustainable and long-lasting.

In generating the general optimal perceived performance model, the optimal perception responses of the respondents were regressed against responses of the approval rating of the facility, purpose of the facility's construction, the purpose achievement status of the facility, the cost worthiness of the facility and the problems encountered by the respondents with the facility. However, in generating the CS optimal perceived performance regression model, the optimal perception responses of class 1 respondents were regressed with the responses of the lasting value of the facility, preservation of historic features of the facility, scenic/aesthetic/environmental features of the facility, structural features of the facility, geometric features of the facility and traffic features of the facility at an $\alpha=0.05$. 


\section{RESULTS AND DISCUSSION}

\section{A. Reliability of the Questionnaire Responses}

The Cronbach's alpha test of internal consistency was run on the ordinal responses of the questionnaire and a value of 0.873 was obtained which indicates a high level of internal consistency for those particular responses as reported in existing works in literature (Laerd Statistics, 2018; Explorable, 2010; Field, 2006; DeVellis, 2003). The questionnaire reliability test result is shown in Table 1.

Table 1: Reliability Statistics.

\begin{tabular}{ccc}
\hline $\begin{array}{c}\text { Cronbach's } \\
\text { Alpha }\end{array}$ & $\begin{array}{c}\text { Cronbach's Alpha } \\
\text { Based on } \\
\text { Standardised Items }\end{array}$ & $\begin{array}{c}\text { Number of } \\
\text { Items }\end{array}$ \\
\hline 0.873 & 0.820 & 21 \\
\hline
\end{tabular}

\section{B. Pearson's Familiarity Correlations}

Table 2 presents the SPSS output of Pearson's correlation coefficients between the degree of familiarity of the respondents with the facility, the number of drives on or under the facility by the respondents and the problems encountered by the respondents while driving or being driven on or under the facility.

Table 2: Pearson's product-moment correlation coefficients between respondents' familiarity, drives and problems with SJGSI.

\begin{tabular}{|c|c|c|c|c|}
\hline & & Familiarity & Drives & Problem \\
\hline \multirow{3}{*}{ Familiarity } & $\begin{array}{l}\text { Pearson } \\
\text { Correlation }\end{array}$ & 1 & 0.125 & -0.011 \\
\hline & Sig. (2-tailed) & & 0.215 & 0.915 \\
\hline & $\mathrm{N}$ & 100 & 100 & 98 \\
\hline \multirow{3}{*}{ Drives } & $\begin{array}{l}\text { Pearson } \\
\text { Correlation }\end{array}$ & 0.125 & 1 & 0.044 \\
\hline & Sig. (2-tailed) & 0.215 & & 0.664 \\
\hline & $\mathrm{N}$ & 100 & 100 & 98 \\
\hline \multirow{3}{*}{ Problem } & $\begin{array}{l}\text { Pearson } \\
\text { Correlation }\end{array}$ & -0.011 & 0.044 & 1 \\
\hline & Sig. (2-tailed) & 0.915 & 0.664 & \\
\hline & $\mathrm{N}$ & 98 & 98 & 98 \\
\hline
\end{tabular}

In traffic engineering, it is a universal fact that when users of a facility frequently drive along with such a facility, they get familiarized with its features and conditions. Consequently, being excellently or very familiar with the facility will make the users at high alert and thus avoid any problem. This condition is more than a hypothesis. Considering the correlation of the number of times that respondents drive or get driven on or under SJGSI and their familiarity with the facility, it was observed that the Pearson correlation coefficient $(r)$ is 0.125 and the significance level is 0.215 . The correlation is positively weak and since $p>0.05$, the notion of regular users of a facility being familiarized with it is just by chance as far as this survey is concerned. Therefore, the number of trips made by the respondents on or under SJGSI is not statistically significant with their familiarity with the facility.

The familiarity of the users of SJGSI is negatively correlated with the number of problems they have encountered with Pearson's coefficient of correlation $r=-0.011$ and $p-$ value of 0.915 . Also, the familiarity of the respondents is uncorrelated and statistically insignificant with the problems they encountered around the vicinity of SJGSI. The number of drives undertaken by the respondents on or under the facility is also weakly correlated to and statistically insignificant with the problems they have encountered.

A possible explanation to these insignificances could be the chronological order of the occurrence of the events. The problems could have been experienced by the respondents before being familiarized with the facility. Therefore, the experience of the problem could probably have made the respondents familiar with the facility before the increase in the intensity of weekly trips (as a new facility). Another explanation for the lack of correlation and the statistical insignificance between the familiarity of the respondents and the problems they have encountered could be attributed to the restrictive geometric feature of the facility such as the narrow lanes and slip roads.

In a CS project, provision would have been made at the planning stage to address the needs and concerns of users such as the provision of guidance signs at important locations of the facility. The facility's elements would have also been designed and constructed based on standard practice. This would have prevented the occurrence of the problems encountered by some of the users.

\section{Pearson's Optimal Perceived Performance Correlations \\ The SPSS output of Pearson's correlation coefficients and the statistical significances is presented in Table 3.}

\begin{tabular}{|c|c|c|c|c|}
\hline & & $\begin{array}{c}\text { Optimal } \\
\text { Performance }\end{array}$ & $\begin{array}{c}\text { Approval } \\
\text { Rating }\end{array}$ & $\begin{array}{c}\text { Cost } \\
\text { Worthiness }\end{array}$ \\
\hline \multirow{3}{*}{$\begin{array}{l}\text { Optimal } \\
\text { Performance }\end{array}$} & $\begin{array}{l}\text { Pearson } \\
\text { Correlation }\end{array}$ & 1 & 0.133 & 0.166 \\
\hline & Sig. (2-tailed) & & 0.192 & 0.102 \\
\hline & $\mathrm{N}$ & 100 & 98 & 98 \\
\hline \multirow{3}{*}{$\begin{array}{l}\text { Approval } \\
\text { Rating }\end{array}$} & $\begin{array}{l}\text { Pearson } \\
\text { Correlation }\end{array}$ & 0.133 & 1 & 0.138 \\
\hline & Sig. (2-tailed) & 0.192 & & 0.176 \\
\hline & $\mathrm{N}$ & 98 & 98 & 97 \\
\hline \multirow{3}{*}{$\begin{array}{l}\text { Cost } \\
\text { Worthiness }\end{array}$} & $\begin{array}{l}\text { Pearson } \\
\text { Correlation }\end{array}$ & 0.166 & 0.138 & 1 \\
\hline & Sig. (2-tailed) & 0.102 & 0.176 & \\
\hline & $\mathrm{N}$ & 98 & 97 & 98 \\
\hline
\end{tabular}

As shown in Table 3, the correlations between the optimal perceived performance and approval rating of SJGSI, between the optimal perceived performance and cost worthiness of the facility and between the cost worthiness and approval rating of the facility are positively weak as none of the Pearson's product-moment correlations reached a value of 0.20 . Moreover, the relationships between the variables are statistically insignificant as both have $p>0.05$. This can be interpreted that the amount of money spent on the facility's construction has no effect on its optimal perceived performance as opined by the respondents. Also, the former and the latter did not affect how the respondents rated the 
facility. Therefore, the amount spent in constructing the facility could, only by chance, affect how it performs optimally and ultimately its rating by the users of the facility.

\section{Pearson's Core CSS Correlations}

Pearson's correlation coefficients and their statistical significances are presented in Table 4.

Table 4: Pearson's product-moment correlation coefficients between CS features of SJGSI expressed by Class 1 respondents.

\begin{tabular}{|c|c|c|c|c|c|c|}
\hline & & FF & $\mathrm{AF}$ & HFP & $\mathrm{TF}$ & SF \\
\hline \multirow{3}{*}{$\mathrm{FF}$} & $\begin{array}{l}\text { Pearson } \\
\text { Correlation }\end{array}$ & 1 & 0.310 & 0.059 & 0.231 & 0.220 \\
\hline & Sig. (2-tailed) & & 0.009 & 0.628 & 0.055 & 0.067 \\
\hline & $\mathrm{N}$ & 70 & 70 & 70 & 70 & 70 \\
\hline \multirow{3}{*}{$\mathrm{AF}$} & $\begin{array}{l}\text { Pearson } \\
\text { Correlation }\end{array}$ & 0.310 & 1 & 0.199 & 0.068 & 0.068 \\
\hline & Sig. (2-tailed) & 0.009 & & 0.099 & 0.578 & 0.579 \\
\hline & $\mathrm{N}$ & 70 & 70 & 70 & 70 & 70 \\
\hline \multirow{3}{*}{ HFP } & $\begin{array}{l}\text { Pearson } \\
\text { Correlation }\end{array}$ & 0.059 & 0.199 & 1 & 0.315 & -0.039 \\
\hline & Sig. (2-tailed) & 0.628 & 0.099 & & 0.008 & 0.749 \\
\hline & $\mathrm{N}$ & 70 & 70 & 70 & 70 & 70 \\
\hline \multirow{3}{*}{$\mathrm{TF}$} & $\begin{array}{l}\text { Pearson } \\
\text { Correlation }\end{array}$ & 0.231 & 0.068 & 0.315 & 1 & 0.424 \\
\hline & Sig. (2-tailed) & 0.055 & 0.578 & 0.008 & & 0.000 \\
\hline & $\mathrm{N}$ & 70 & 70 & 70 & 70 & 70 \\
\hline \multirow{3}{*}{ SF } & $\begin{array}{l}\text { Pearson } \\
\text { Correlation }\end{array}$ & 0.220 & 0.068 & -0.039 & 0.424 & 1 \\
\hline & Sig. (2-tailed) & 0.067 & 0.579 & 0.749 & 0.000 & \\
\hline & $\mathrm{N}$ & 70 & 70 & 70 & 70 & 70 \\
\hline
\end{tabular}

Legend: FF - Facility's Fitness, AF - Aesthetic Features, HFP - Historic

Features Preservation, TF - Traffic Feature, SF - Safety Feature

The physical fitness of SJGSI at its location is moderately correlated to its aesthetics with $r=0.310$ and $p=0.009$ at a 0.05 significance level. There is a statistically significant relationship between the facility's physical fitness and its aesthetics as the SJGSI has reflected the surrounding features. The context is an urban environment and as such the facility was designed and constructed with urban features such as the innovative Observation Post at loop D.

There is very weak correlation between the facility's physical fitness and the preservation of historic features at its location because $r=0.059$. The two CS outcomes are statistically insignificant. With the re-erection of the iconic Silver Jubilee structure and reconstruction of Kofar Nasarawa, the physical fitness of the facility is not in any way enhanced or degraded. However, the aesthetics of the facility are weakly enhanced with the preservation of these historic features with $r \approx 0.2$ but with no obvious statistical significance $(p=0.099)$.

Traffic movement is weakly correlated with the physical fitness of the facility $(r=0.231)$ and the two are statistically insignificant $(p=0.055)$. With $88 \%$ of respondents opining that the main purpose of constructing the facility at the location is to ease or solve the problem of congestion and $89 \%$ saying that the purpose has been achieved, the weak correlation is somewhat justified because the location of the facility has little to do with the traffic flow parameters. The aesthetic features of the facility are not correlated and are statistically insignificant with the traffic movements within the facility $(r$ $=0.068$ and $p=0.578$ ). The traffic movements are, however, weakly correlated with the preservation of the historic features at the facility's location. This is statistically significant because while the historic features were preserved, the mobility of road users was not affected with the preservation.

The safe movement of traffic within the facility is weakly correlated with the facility's physical fitness but with no statistical significance between the two $(r=0.220$ and $p=$ 0.067). A similar case was observed between safety and aesthetics of the facility ( $r=0.068$ and $p=0.579)$. However, safety is negatively correlated with the preservation of historic features with no statistical significance. Although the value of the correlation is closer to zero the preservation of the historic features could be the factor responsible for the reduced safety of the facility at a very negligible measure.

\section{E. General Optimal Perceived Performance Regression Model}

The results of the regression analysis carried out on the general optimal perceived performance of SJGSI and its independent variables are presented in Tables 5 - 8 .

\begin{tabular}{|c|c|c|c|}
\hline Model & $\begin{array}{l}\text { Variables } \\
\text { Entered }\end{array}$ & Variables Removed & Method \\
\hline 1 & $\begin{array}{c}\text { Approval Rating, } \\
\text { Purpose, Cost } \\
\text { Worthiness, Problem, } \\
\text { Purpose Achievement } \\
\end{array}$ & - & Enter \\
\hline
\end{tabular}

Table 6: General optimal perceived performance model summary.

\begin{tabular}{ccccc}
\hline Model & $\mathrm{r}$ & $\mathrm{r}$ Squared & $\begin{array}{c}\text { Adjusted R } \\
\text { Squared }\end{array}$ & $\begin{array}{c}\text { Std. Error of the } \\
\text { Estimate }\end{array}$ \\
\hline 1 & 0.415 & 0.172 & 0.125 & 0.422 \\
\hline
\end{tabular}

The general perceived performance model expression is given in Eq. (3).

$$
\begin{aligned}
Y_{G}= & 0.159 X_{1}+0.066 X_{2}+0.498 X_{3}+0.144 X_{4} \\
& -0.005 X_{5}-0.242
\end{aligned}
$$

where: $Y_{G}=$ general optimal perceived performance of SJGSI, $X_{1}=$ problems encountered by respondents, $X_{2}=$ main purpose of constructing the facility, $X_{3}=$ achievement status of the main purpose of constructing the facility, $X_{4}=$ cost worthiness of the facility, $X_{5}=$ approval rating of the facility by the respondents.

From Table 6, Pearson's product-moment coefficient correlation is $r=0.415$ indicating a near strong correlation between the independent and dependent variables based on Arkkelin (2014). The r-squared value $\left(r^{2}=0.172\right)$ indicates the percentage that the independent and dependent variables share (out of possible $100 \%$, if each of the same variables was correlated with itself). Therefore, the shared variance is $17.2 \%$.

The ANOVA result shown in Table 7 was used to establish whether the findings might have arisen from sampling error. It was established whether the regression line is different from zero. If it is, then it is claimed that the findings have not arisen from a sampling error. From Table 7, the $F$ - 
Table 7: General optimal perceived performance ANOVA result.

\begin{tabular}{ccccccc}
\hline \multirow{2}{*}{ Model } & $\begin{array}{c}\text { Sum of } \\
\text { Squares }\end{array}$ & df & $\begin{array}{c}\text { Mean } \\
\text { Square }\end{array}$ & F & Sig. \\
\hline \multirow{4}{*}{1} & Regression & 3.227 & 5 & 0.645 & 3.622 & 0.005 \\
Residual & 15.504 & 87 & 0.178 & & \\
& Total & 18.731 & 92 & & & \\
\hline
\end{tabular}

Table 8: General optimal perceived performance coefficients.

\begin{tabular}{ccccccc}
\hline \multirow{2}{*}{ Model } & \multicolumn{2}{c}{$\begin{array}{c}\text { Unstd. } \\
\text { Coefficients }\end{array}$} & $\begin{array}{c}\text { Std. } \\
\text { Coefficient } \\
\text { s }\end{array}$ & $\mathrm{t}$ & Sig. \\
\cline { 2 - 5 } & $\mathrm{B}$ & Std. Error & Beta & & \\
\hline (Constant) & -0.242 & 0.388 & & - & 0.534 \\
& Problem & 0.159 & 0.097 & 0.166 & 1.635 & 0.106 \\
1 & $\begin{array}{c}\text { Purpose } \\
\text { Purpose }\end{array}$ & 0.066 & 0.063 & 0.104 & 1.040 & 0.301 \\
Achievement & 0.498 & 0.164 & 0.311 & 3.032 & 0.003 \\
Cost Worthiness & 0.144 & 0.099 & 0.144 & 1.457 & 0.149 \\
Approval Rating & -0.005 & 0.061 & -0.009 & - & 0.087 & 0.931 \\
\hline
\end{tabular}

value $=3.622$ and the confidence value, $p=0.005$ (very significant). The result of the regression is not by chance thus.

From Table 8, the constant value of -0.242 is the predicted score on the general optimal perceived performance of SJGSI if none of the independent variables was considered and it has no statistical significance. This could be in the form of an unwanted scenario such as accident, congestion or even structural failure of the facility. Considering the other $B$ values, that is, coefficients of the independent variables, the following conclusions were drawn:

(i) The absence of a problem experienced by a user affects the optimal perceived performance by 0.159 unit without any statistical significance $(B=0.166, t=1.635, p=$ $0.106)$.

(ii) The main purpose of constructing the facility affects its optimal perceived performance by 0.066 unit without any statistical significance $(B=0.066, t=1.040, p=0.301)$.

(iii) The achievement of the purpose of the facility affects its optimal perceived performance almost by half with a considerable statistical significance $(B=0.498, t=3.032$, $p=0.003$ ).

(iv) The cost worthiness of the facility affects its optimal perceived performance by 0.144 unit without a statistical significance $(B=0.144, t=1.457, p=0.149)$.

(v) The effect of the approval rating on the facility's optimal perceived performance is almost negligible without a statistical significance $(B=-0.005, t=-0.087, p=0.931)$.

From the foregoing, it could be interpreted that the main purpose of constructing the facility was to solve the problem of congestion as opined by $88 \%$ of the respondents, while 89 $\%$ of the respondents believed that the purpose was achieved. This significantly affects the optimal perceived performance of the facility and it could be accurately predicted since it was not by chance. All the other predictors of the optimal perceived performance affect the optimal performance by chance.

\section{F. CS Optimal Performance Regression Model}

Tables 9 to 12 presents the results of the regression analysis and subsequent interpretive discussions follow.

Table 9: CS Optimal perceived performance variables entered/removed.

\begin{tabular}{|c|c|c|c|}
\hline Model & $\begin{array}{l}\text { Variables } \\
\text { Entered }\end{array}$ & $\begin{array}{l}\text { Variables } \\
\text { Removed }\end{array}$ & Method \\
\hline 1 & $\begin{array}{l}\text { Lasting Value, Historic } \\
\text { Features Preservation, } \\
\text { Scenic Aesthetic } \\
\text { Environmental, Safety, } \\
\text { Structural, Geometric, } \\
\text { Traffic }\end{array}$ & 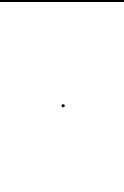 & Enter \\
\hline
\end{tabular}

Table 10: CS Optimal Perceived Performance Model Summary.

\begin{tabular}{ccccc}
\hline Model & $\mathrm{r}$ & $\mathrm{r}$ Squared & Adjusted r Squared & $\begin{array}{c}\text { Std. Error of the } \\
\text { Estimate }\end{array}$ \\
\hline 1 & 0.374 & 0.140 & 0.039 & 0.456 \\
\hline
\end{tabular}

Table 11: CS optimal perceived performance ANOVA.

\begin{tabular}{ccccccc}
\hline \multirow{2}{*}{ Model } & $\begin{array}{c}\text { Sum of } \\
\text { Squares }\end{array}$ & df & Mean Square & F & Sig. \\
\hline \multirow{2}{*}{1} & Regression & 2.025 & 7 & 0.289 & 1.390 & 0.226 \\
& Residual & 12.489 & 60 & 0.208 & & \\
& Total & 14.515 & 67 & & & \\
\hline
\end{tabular}

Table 12: CS Optimal perceived performance coefficients.

\begin{tabular}{|c|c|c|c|c|c|c|}
\hline & \multirow{2}{*}{ Model } & \multicolumn{2}{|c|}{$\begin{array}{c}\text { Unstd. } \\
\text { Coefficients }\end{array}$} & \multirow{2}{*}{$\begin{array}{c}\begin{array}{c}\text { Std. } \\
\text { Coefficients }\end{array} \\
\text { Beta }\end{array}$} & \multirow{2}{*}{$\mathrm{t}$} & \multirow{2}{*}{ Sig. } \\
\hline & & B & $\begin{array}{c}\text { Std. } \\
\text { Error }\end{array}$ & & & \\
\hline \multirow{8}{*}{1} & (Constant) & 0.643 & 0.423 & & 1.518 & 0.134 \\
\hline & $\begin{array}{l}\text { Historic Features } \\
\text { Preservation }\end{array}$ & 0.067 & 0.056 & 0.157 & 1.199 & 0.235 \\
\hline & Geometric & 0.138 & 0.115 & 0.183 & 1.207 & 0.232 \\
\hline & Structural & -0.218 & 0.129 & -0.236 & -1.691 & 0.096 \\
\hline & $\begin{array}{l}\text { Scenic, Aesthetic } \\
\text { and Environmental }\end{array}$ & -0.143 & 0.115 & -0.172 & -1.246 & 0.218 \\
\hline & Traffic & 0.066 & 0.143 & 0.071 & 0.459 & 0.648 \\
\hline & Safety & 0.043 & 0.121 & 0.053 & 0.355 & 0.724 \\
\hline & Lasting Value & 0.067 & 0.128 & 0.071 & 0.525 & 0.602 \\
\hline
\end{tabular}

The CS perceived performance model of SJGSI is expressed in Eq. (4).

$$
\begin{aligned}
Y_{C S}= & 0.067 X_{1}+0.138 X_{2}-0.218 X_{3}-0.143 X_{4} \\
& +0.066 X_{5}+0.043 X_{6}+0.067 X_{7}+0.643
\end{aligned}
$$

where: $Y_{C S}=\mathrm{CS}$ optimal perceived performance of SJGSI, $X_{1}$ $=$ historic features preservation of the facility, $X_{2}=$ geometric property of the facility, $X_{3}=$ structural feature of the facility, $X_{4}=$ scenic, aesthetic and environmental features of the facility, $X_{5}=$ traffic/mobility feature of the facility, $X_{6}=$ safety feature of the facility, and $X_{7}=$ sustainability of SJGSI

Hypothetically and for an ideal CS facility, the perceived performance is a dependent variable determined by certain predictors, which include: 
(i) The extent to which the facility preserved the delicate historic features at its location.

(ii) How excellent the geometry of the facility is for the smooth flow of traffic.

(iii) The structural strength and durability of the facility.

(iv) The ease with which users use the facility.

(v) The lasting value of the facility.

(vi) How safe the facility is for all user groups?

(vii) The scenic and aesthetic features of the facility and its environmental harmony.

From Table 10, it can be seen that there is a moderate correlation between the optimal perceived performance of SJGSI and its determinants of the perception with $r=0.374$. The relationship between the optimal perceived performance of SJGSI and its predictors is by chance because from the ANOVA results, $F=1.390$ and $p=0.226$ (not significant). From Table 12, the preservation of the iconic Silver Jubilee structure and the ancient Kofar Nasarawa affects the CS optimal perceived performance of SJGSI by 0.067 unit without any statistical significance $(p=0.235)$. The geometry of the facility affects its CS optimal performance by 0.138 unit without any statistical significance $(p=0.232)$. The CS optimal perceived performance of SJGSI is negatively affected by its structural condition by 0.218 unit insignificantly ( $p=$ 0.096). The CS optimal perceived performance of SJGSI is negatively affected by its scenic, environmental and aesthetic features by 0.143 unit insignificantly $(p=0.218)$. The traffic feature of SJGSI affects its CS optimal users' perceived performance by 0.066 unit insignificantly $(p=0.648)$. The SJGSI contributes 0.043 unit of safety to its CS optimal perceived performance insignificantly $(p=0.724)$. The lasting value of SJGSI affects the CS optimal performance by 0.067 unit without any statistical significance.

It is apparent that most of the CS outcomes of SJGSI affects the optimal perceived performance of the facility by mere chance because the facility was not planned based on CS concept and there exist no standard methods of measuring the outcomes during its perceived operational performance.

\section{CONCLUSION}

Based on the study conducted and the results obtained, the following conclusions were drawn:

(i) Public complaints about the perceived operational performance of SJGSI are valid within the confines of transportation engineering. The complaints were validated through an analysis of questionnaire data and visual inventory of the facility as well as observation of traffic movements within its proximity using CSS principles.

(ii) The study established that CSS concept was not employed during the planning of SJGSI, which validates the public complaints on the facility's perceived operational performance.

(iii) There exists a correlation between the planning of SJGSI and its operational performance, albeit inferentially. If a robust, standard and extensive CS planning exercise was carried out with full implementation and monitoring during design and construction, some of the public complaints on the facility's problems and flaws would not have validly arisen.

\section{RECOMMENDATIONS}

(i) For future transportation projects, governments at various levels of governance (through the States' and Federal Ministries of Works and Transportation) could consider adopting CSS concept and principles in the planning of such projects. The technique could be diligently studied and modified to suit our peculiar situation.

(ii) In the academia, the Universities through the Nigerian Universities Commission (NUC) could also consider the prospects and possibility of incorporating CSS into the curricula of transportation engineering and engineering project management courses. This will impart positively an awareness on graduates-to-be of the immense benefits and outcomes of using CSS in transportation development processes.

(iii) For effective and general widespread adoption and implementation of CSS, the relevant law-making bodies, at both federal and state levels, could openly and comprehensively debate on CSS and enact suitable laws to be strictly adhered to by all the relevant transportation bodies and at all stages of transportation development processes.

(iv) To improve the operational perception of SJGSI, traffic signs (directional, informative and warning signages) should be installed at appropriate locations to serve as guides to users of the facility to their respective destinations. Possible expandable sections (such as the atgrade portions) should be expanded to accommodate more traffic and improve LOS. Also, the public should be enlightened through the mass media on how to effectively and safely use the facility by humbly obeying all traffic rules and regulations within the facility's vicinity.

\section{REFERENCES}

Al-Kaisy, A. and Roefaro, S. (2012). Channelised RightTurn Lanes at Signalised Intersections: The U.S. Experience. International Journal on Advances in Transportation Studies. B 26: $57-68$.

Arkkelin, D. (2014). Using SPSS to Understand Research and Data Analysis. Psychology Curricular Materials. Book 1. Valparaiso University.

Böhler-Baedeker, S. and Lindenau, M. (2013). Addressing Key Challenges of Sustainable Urban Mobility Planning: Why is Participation a Challenge in Urban Mobility Planning? Transport Engineering Institute for Transport Studies, University of Leeds.

Burgess, T. F. (2001). A General Introduction to the Design of Questionnaires for Survey Research. Guide to the Design of Questionnaires. Information Systems Services, University of Leeds.

Classen, S.; D. W. Eby; L. J. Molnar; B. M. Dobbs and S. M. Winter. (2011). Transportation and Ageing: Exploring Stakeholders' Perspectives on Advancing Safe Mobility. South African Journal of Occupational Therapy. 41(3). 18 24. 
Cochran, W. G. (1977). Sampling Techniques. $3^{\text {rd }}$ Edition. John Wiley and Sons Inc. New York, USA.

DeVellis, R. (2003). Scale Development: Theory and Applications. Thousand Okas, CA. Sage. California, USA.

Dondi, G.; A. Simone; C. Lantieri and V. Vignali. (2011). Bike Lane Design: The Context Sensitive Approach. 2011 International Conference on Green Buildings and Sustainable Cities. Procedia Engineering, Elsevier Journal. 21: $897-906$.

Explorable (2010). Cronbach's Alpha. Retrieved from https://explorable.com/cronbachs-alpha. $\quad$ Accessed 29 February, 2020.

Federal Highway Administration (2017). Context Sensitive Solutions. Retrieved from https://www.fhwa.dot.gov/planning/css/index.cfm. Accessed 07 March, 2018.

Field, A. (2006). C8057 (Research Methods II): Reliability Analysis using SPSS. Statisticshell.com.

Fryrear, A. (2015). What is a Good Survey Response Rate? Survey Gizmo/Resources. Retrieved from https://www.surveygizmo.com/resources/blog/surveyresponse-rate/. Accessed 26 March 2018.

Georgia Department of Transportation (2016). Context Sensitive Design Online Manual. Atlanta, Georgia 30308. Second Revision.

Laerd Statistics (2018). Cronbach's Alpha ( $\alpha$ ) Using SPSS Statistics. Retrieved from https://statistics.laerd.com/spss-tutorials/cronbachs-alphausing-spss-statistics.php. Accessed 29 February, 2020.

Maryland Department of Transportation - MDOT (1998). Context Sensitive Design - Thinking Beyond the Pavement. State Highway Administration.

Michael, D. M. (2016). Transportation Planning Handbook. Fourth Edition. John Wiley and Sons Inc. Hoboken, New Jersey.
Miller R. L.; C. Acton; D. A. Fullerton and M. John. (2002). SPSS for Social Scientists. $1^{\text {st }}$ Edition. Palgrave Macmillan. Houndmills, Basingstoke, Hampshire RG21 6XS and 175 Fifth Avenue, New York, N. Y. 10010.

Montana Department of Transportation - MDT (2015). Context Sensitive Solutions Guide. MDT.

Siniscalco, M. T. and Auriat, N. (2005). Questionnaire Design. Quantitative Research Methods in Educational Planning. UNESCO International Institute of Educational Planning. 7 - 9 rue Eugene-Delacroix, 75116 Paris, France.

Stamatiadis, N.; A. Kirk; D. Hartman; T. Hopwood and J. Pigman. (2009). Quantifying the Benefits of Context Sensitive Solutions. NCHRP Report 642. Washington, D.C.: Transportation Research Board.

Stefanowski, J. (2013). Analysis of Questionnaires and Qualitative Data - Non-Parametric Tests. Information Institute, Poznańska Polytechnic.

Virginia Department of Transportation (2016). Common Sense Engineering (CSE) and Context Sensitive Solutions (CSS) to Transportation Challenges. Instructional and Informational Memorandum. Location and Design Division.

Wolf, K. L. (2006). Assessing Public Response to Freeway Roadside: Urban Forestry and Context Sensitive Solutions. Transportation Research Record. Journal of the Transportation Research Board. No. 1984, Transportation Research Board of the National Academies, Washington, D. C. P. $102-111$.

Xia, J. (2014). A Synthesis of the State-of-the-Practice for Advancing Planning and Operations Integration Opportunities within Transportation Agencies. Florida International University. 10555 E Flagler St., EC 3603, Miami, FL 33174. 